\title{
RESEARCH
}

Open Access

\section{Insulin-like growth factors and related proteins in plasma and cerebrospinal fluids of HIV-positive individuals}

Hyeon-Sook Suh', Yungtai Lo ${ }^{2}$, Namjong Choi ${ }^{1}$, Scott Letendre ${ }^{3}$ and Sunhee C Lee ${ }^{1 *}$

\begin{abstract}
Background: Clinically significant dysregulation of the insulin-like growth factor (IGF) family proteins occurs in HIV-infected individuals, but the details including whether the deficiencies in IGFs contribute to CNS dysfunction are unknown.

Methods: We measured the levels of IGF1, IGF2, IGFBP1, IGFBP2, and IGF2 receptor (IGF2R) in matching plasma and cerebrospinal fluid (CSF) samples of $107 \mathrm{HIV}+$ individuals from CNS HIV Antiretroviral Therapy Effects Research (CHARTER) and analyzed their associations with demographic and disease characteristics, as well as levels of several soluble inflammatory mediators (TNFa, IL-6, IL-10, IL-17, IP-10, MCP-1, and progranulin). We also determined whether IGF1 or IGF2 deficiency is associated with HIV-associated neurocognitive disorder (HAND) and whether the levels of soluble IGF2R (an IGF scavenging receptor, which we also have found to be a cofactor for HIV infection in vitro) correlate with HIV viral load (VL).
\end{abstract}

Results: There was a positive correlation between the levels of IGF-binding proteins (IGFBPs) and those of inflammatory mediators: between plasma IGFBP1 and IL-17 ( $\beta$ coefficient 0.28, $P=0.009$ ), plasma IGFBP2 and IL-6 ( $\beta$ coefficient 0.209, $P=0.021$ ), CSF IGFBP1 and TNFa ( $\beta$ coefficient $0.394, P<0.001)$, and CSF IGFBP2 and TNF-a ( $\beta$ coefficient $0.14, P<0.001)$. As IGFBPs limit IGF availability, these results suggest that inflammation is a significant factor that modulates IGF protein expression/availability in the setting of HIV infection. However, there was no significant association between HAND and the reduced levels of plasma IGF1, IGF2, or CSF IGF1, suggesting a limited power of our study. Interestingly, plasma IGF1 was significantly reduced in subjects on non-nucleoside reverse transcriptase inhibitor-based antiretroviral therapy (ART) compared to protease inhibitor-based therapy $(174.1 \pm 59.8$ vs. $202.8 \pm 47.3 \mathrm{ng} / \mathrm{ml}, P=0.008)$, suggesting a scenario in which ART regimen-related toxicity can contribute to HAND. Plasma IGF2R levels were positively correlated with plasma $V L$ ( $\beta$ coefficient $0.37, P=0.021$ ) and inversely correlated with current CD4+ T cell counts ( $\beta$ coefficient $-0.04, P=0.021$ ), supporting our previous findings in vitro.

Conclusions: Together, these results strongly implicate (1) an inverse relationship between inflammation and IGF growth factor availability and the contribution of IGF deficiencies to HAND and (2) the role of IGF2R in HIV infection and as a surrogate biomarker for HIV VL.

Keywords: Biomarker, Growth factor, Cytokines, Neurocognitive impairment, Charter

\footnotetext{
* Correspondence: sunhee.lee@einstein.yu.edu

'Department of Pathology, Albert Einstein College of Medicine, Bronx, NY 10461, USA

Full list of author information is available at the end of the article
}

\section{Biomed Central}

(c) 2015 Suh et al.; licensee BioMed Central. This is an Open Access article distributed under the terms of the Creative Commons Attribution License (http://creativecommons.org/licenses/by/4.0), which permits unrestricted use, distribution, and reproduction in any medium, provided the original work is properly credited. The Creative Commons Public Domain Dedication waiver (http://creativecommons.org/publicdomain/zero/1.0/) applies to the data made available in this article, unless otherwise stated. 


\section{Background}

The insulin-like growth factor (IGF) system consists of growth peptides (IGF1 and IGF2), their receptors (IGF1R and IGF2R), and circulating binding proteins (IGFBPs 1-6) [1-3]. Multiple factors influence IGF levels in biological fluids including nutrition, endocrine status, liver disease, chronic inflammatory diseases, diabetes mellitus, and ethnicity (African American $<$ Asian $<$ Caucasian) [4]. Plasma levels of IGFs are much higher (10 to 100 fold) than required for biological action, as the majority are bound to IGF-binding proteins (IGFBPs) [5,6]. Most circulating IGF1 is produced by the liver, which is under the regulation of pituitary growth hormone (GH). Extrahepatic (non-GH-dependent) IGF1 synthesis also occurs [3]. IGF2 is also produced from hepatic and extrahepatic sources but its production is not tightly regulated by GH [7]. IGF1 and IGF2 are also synthesized in the CNS and surrounding cells [8-10] and have neurotrophic effects [11-14]. Both IGF1 and IGF2 signal through IGF1R, whereas IGF2R is a non-signaling receptor involved in the removal of excess IGF2 during development $[15,16]$. IGFBPs regulate the biological activity of IGFs by controlling IGF efflux from the vascular space, regulating IGF clearance, and modulating interaction of IGFs with their receptors $[17,18]$. The liver is a major site of synthesis for IGFBP1. IGFBP1 has been proposed as a dynamic regulator of IGF bioactivity in vivo. IGFBP1 may be partly responsible for the decrease in lean body mass observed in catabolic/inflammatory conditions associated with low IGF1. Proinflammatory cytokines can directly enhance IGFBP-1 synthesis [19,20]. IGFBP2 also modulates IGF1 activity [21]. In the brain, IGFBPs are produced by neurons, glial cells, choroid plexus epithelia, and cerebral blood vessels [3]. IGFBP2 is the most abundant IGFBP in the CNS/cerebrospinal fluid (CSF) [18].

There is evidence that reduced IGF1 levels correlate with impaired cognitive function in adults $[22,23]$. Alzheimer's patients show increased serum TNFa and decreased IGF1 levels, with the two showing a negative correlation [22]. In a study of motor neuron disease, CSF (but not serum) levels of IGF1 were diminished [23]. Uptake of circulating IGF1 into the CSF can be substantial and circulating IGF1 could aid brain function $[24,25]$. This may explain why circulating IGF1 levels correlate with deterioration of cognitive functioning in elderly patients [26].

IGFs and related factors have been studied in the context of HIV infection and associated diseases, as they may play a role in the immune response to HIV and influence the rate of HIV disease progression [27,28]. HIV/AIDS is associated with reduced IGF1 and IGF2 levels [7,28]. Dysregulation of IGF1 also contributes to metabolic syndromes and lipodystrophy in these individuals $[7,29,30]$. IGFBP1 and IGFBP2 may also function as proinflammatory factors correlating with HIV disease activity [31-33].
The effect of antiretroviral therapy (ART) on IGF proteins can also be substantial $[34,35]$. Specifically, certain types of ART have been linked to lipodystrophy [36,37], vitamin D deficiency, and reduced serum IGF1 levels [38,39].

Little or no information is available on the role of IGFs and related proteins in neuroAIDS. HIV-associated neurocognitive disorder (HAND) affects approximately 50\% of HIV+ individuals through several different mechanisms [40-42]. Intact virus and viral components as well as host inflammatory mediators and ART have all been implicated. There is a pressing need to identify clinically useful biomarkers for HAND. Studies by this and other laboratories suggest that depletion of neuronal growth factors might contribute to the development of HAND. Specifically, we have shown that the essential CNS growth factor progranulin is deficient in the CSF of HIVundetectable adults with neurocognitive impairment (NCI) but not HIV-detectable adults with HAND [43,44]. Both progranulin and IGF1 are produced by microglia and modulated by inflammatory mechanisms $[13,45]$. A related protein IGF2 can replace IGF1 for IGF1R signaling and neuroprotection [13]. IGF2R that is normally expressed by neurons alone in the CNS is highly upregulated in microglia in HIV encephalitis and functions as a cofactor for HIV infection [46]. High levels of (soluble) IGF2R are present in blood, urine, and amniotic fluid $[47,48]$, suggesting its potential usefulness as a biomarker.

The purpose of this study was to determine whether IGF1 or IGF2 deficiency exists in HIV+ individuals, especially in the context of neurocognitive dysfunction (HAND) and to examine the relationship between IGFs (IGF1 and IGF2) and IGFBPs (IGFBP1 and IGFBP2) in a well-characterized HIV+ cohort. We hypothesized that reduced levels of IGF1 in plasma or CSF (or both) would be associated with HAND and that chronic inflammation state in HIV infection would contribute to this. In addition, given the novel finding that IGF2R is upregulated in activated microglia and macrophages and functions as an HIV cofactor, we examined the association between IGF2R levels and HIV viral load (VL).

\section{Methods}

\section{CHARTER subjects}

CSF and plasma pairs were collected from 107 adults enrolled in the cross-sectional component of the CNS HIV Antiretroviral Therapy Effects Research (CHARTER) cohort, a six-center, US-based project funded by the National Institutes of Health. The project was approved by the institutional review board (IRB) of each participating institution (Johns Hopkins University, Mt. Sinai School of Medicine, University of California, San Diego, University of Texas Medical Branch-Galveston, University of Washington, and Washington University), as well as Albert Einstein College of Medicine. All participants provided written informed 
consent. Individuals with abnormal serum glucose, HCV seropositivity, or current substance use (based on urine drug screening) were excluded. Individuals receiving human growth hormone (GH), GH releasing factor, or hematopoietic growth factors such as erythropoietin were also excluded.

\section{Neuropsychological testing}

All participants completed a comprehensive neurocognitive test battery (speed of Information processing, learning and memory, executive functions, language, working memory, motor, self-report questionnaires, psychiatric interviews), covering seven cognitive domains that are commonly affected by HIV. The best available normative standards were used, which correct for effects of age, education, gender, and ethnicity, as appropriate. Test scores were automatically converted to demographically corrected standard scores (T-scores) using available computer programs. To classify presence and severity of neurocognitive impairment, a published objective algorithm that has been shown to yield excellent interrater reliability in previous multisite studies [49] was applied. This algorithm conforms to the Frascati criteria for diagnosing HAND [42], which requires presence of a least mild impairment in at least two domains.

\section{IGF1 ELISA}

IGF1 levels were quantified by enzyme-linked immunosorbent assay (ELISA, ALPCO Diagnostics, Salem, NH, USA: cat \# 22-IGFHU-E01, sensitivity 90 pg/ml) using the core service of the Einstein Diabetes Research Center (Biomarker Analytic Research Core). We measured total IGF1 levels, that is, free and IGFBP-associated, following the manufacturer's instructions. Briefly, ALPCO kits separate IGF1 from IGFBPs by acidification. Re-association of IGF1 with IGFBPs (after restoration of neutral $\mathrm{pH}$ ) is prevented with an excess of IGF2. IGF2 blocks the access of IGF1 to the IGFBP binding sites without interfering with the IGF1-specific antibodies used in the assay. Samples were assayed in duplicate.

\section{IGF2 ELISA}

IGF2 levels were also quantified by ELISA (ALPCO Diagnostics, NH: cat \# 22-IGF-E30, sensitivity $20 \mathrm{pg} / \mathrm{ml}$ ) using the core service of the Einstein Diabetes Research Center (Biomarker Analytic Research Core, Bronx, NY, USA). Similar to IGF1 ELISA, results do not depend on the binding protein concentration of the sample. There is no cross-reactivity with IGF1. IGF2 was separated from the binding proteins by acidification, and reassociation of the freed binding proteins with IGF2 was prevented by excess IGF1. Samples were assayed in duplicate.

\section{IGF2R ELISA}

Soluble IGF2R levels were quantified by ELISA (R\&D Systems, Minneapolis, MN, USA: cat \#DY 2447, sensitivity approximately $150 \mathrm{pg} / \mathrm{ml}$ ), following the manufacturer's instructions. The samples were diluted until the values fell within the linear range of detection (approximately 1:80 for plasma and approximately 1:10 for CSF).

\section{Other biomarker quantifications}

Concentrations of inflammatory mediators were determined in the plasma and CSF samples of all 107 subjects, as previously reported [43]. A multiplex bead array quantified concentrations of IFN $\gamma$, IL-1 $\beta$, IL-4, IL-6, IL-10, IL13, IL-17, TNF $\alpha$, CCL2/MCP-1, CXCL10/IP-10, IGFBP1, and IGFBP2 (EMD Millipore, Billerica, MA, USA). Samples were diluted until the final concentrations were within the linear range of detection for the assay. Progranulin was measured by ELISA (DY2420, R\&D Systems), as reported [43]. All samples were tested in duplicate and concentrations interpolated from a standard curve constructed by four-parameter fitting of internal standards.

\section{Data analysis}

Inflammatory mediators whose levels were below the detection limit of the assay in $>90 \%$ of samples were excluded from analysis. These were IL-1 $\beta$, IL-4, and IL-13 for plasma and IL-1 $\beta$, IL-4, IL-13, IFN $\gamma$, and IL-17 for CSF. Undetectable HIV VL designates HIV RNA levels below 50 copies $/ \mathrm{ml}$, the lower limit of quantification (Amplicor, Roche Diagnostics, Indianapolis, IN, USA).

For normalization, plasma IGFBP1, plasma IGF2R, CSF IGF2, and CSF IGFBP2 concentration values were transformed with natural logarithms, and CSF IGF2R values were square-root transformed. Differences in demographic characteristics, AIDS status, current CD4 count, HIV VL, alcohol dependence, albumin, AST, ALT, and IGF1 levels in the plasma and CSF between HIV-infected individuals with and without neurocognitive impairment were examined using $t$-tests or Wilcoxon rank-sum tests for continuous variables and using chi-squared or Fisher's exact tests for categorical variables. Initial analysis of associations of demographic and disease characteristics with plasma and CSF IGF protein concentrations were examined using $t$-tests or Wilcoxon rank-sum tests for categorical variables and Spearman correlation coefficients for continuous variables. Linear regression models or analysis of covariances (ANCOVA) were used to examine associations of IGF proteins with neurocognitive status adjusted for demographics, HIV VL, and inflammatory mediators. Variables with a $P$-value $\leq 0.2$ in initial analysis were included in multivariate analysis. Because neither log-transformation nor square root transformation normalized CSF IGF1, CSF IGFBP1, or plasma IGFBP2, non-parametric analysis of covariances was 
used for these three variables. Statistical analyses were performed using SAS (version 9.1, SAS Institute, Cary, NC, USA) software.

\section{Results}

Demographic and clinical characteristics of HIV+ individuals in the cohort

The demographic and clinical characteristics of HIV+ individuals in the cohort are listed in Table 1 . This cohort is identical to that used for our recent progranulin study [43]. Additional factors that are relevant to IGF analysis (such as BMI, liver function tests) are also listed. Individuals with $\mathrm{HCV}$ infection are excluded from the study. When the characteristics were stratified by NC impairment, there were no significant differences between individuals with and without $\mathrm{NC}$ impairment, except age. Individuals with $\mathrm{NC}$ impairment were older than those without NC impairment (45.3 \pm 9.3 vs. $41.8 \pm$ 7.6, $P=0.033$ ) (Table 1).

\section{Measurement of IGFs and related proteins in plasma and CSF}

The raw values for the IGFs and related proteins measured in plasma and CSF are listed in Table 2. As these factors are infrequently measured, especially in CSF, we listed the available references for comparison. The levels measured in our study are in general agreements with those reported. The median plasma IGF1 and IGF2 levels had the known ratio of approximately 1:3. The CSF IGF1 levels were extremely low, representing approximately $1 / 200$ of the plasma level. The CSF IGF2 and IGFBP1 were approximately $1 / 20$ and approximately $1 / 7$ of the plasma levels, respectively, and the CSF IGFBP2 levels were approximately 2.3 -fold higher than plasma levels, suggesting that IGF2 and IGFBP2 play more significant roles in the CNS relative to IGF1 and IGFBP1. The median CSF IGF2R level was $6.65 \mathrm{ng} / \mathrm{ml}$ and represented approximately $1 / 20$ of the plasma levels. To our knowledge, this is the first reported measurement of IGF2R levels in CSF.

\section{IGFs and related proteins in subjects with or without NC impairment}

We next compared the levels of IGFs and related proteins in subjects with or without NC impairment to determine whether the levels of any of these factors differ in the two groups. The results showed no significant differences in plasma or CSF IGFs in the two groups (Table 3). Although the median CSF IGF1 levels were reduced in the subgroup with $\mathrm{NC}$ impairment compared

Table 1 Demographic and clinical characteristics (combined and stratified by neurocognitive impairment)

\begin{tabular}{|c|c|c|c|c|}
\hline Characteristics & $\begin{array}{l}\text { All subjects } \\
(n=107)\end{array}$ & $\begin{array}{l}\text { NC impaired } \\
(n=58)\end{array}$ & $\begin{array}{l}\text { NC unimpaired } \\
(n=49)\end{array}$ & $P$ value \\
\hline Age, years - mean $\pm S D$ & $43.7 \pm 8.7$ & $45.3 \pm 9.3$ & $41.8 \pm 7.6$ & 0.033 \\
\hline Gender, male - N (\%) & $93(86.9 \%)$ & $52(89.7 \%)$ & $42(85.7 \%)$ & 0.406 \\
\hline \multicolumn{5}{|l|}{ Race } \\
\hline White - N (\%) & $59(55.1 \%)$ & $31(53.5 \%)$ & $28(57.1 \%)$ & \multirow[t]{3}{*}{0.962} \\
\hline Black & $34(31.8 \%)$ & $18(31.0 \%)$ & $16(32.7 \%)$ & \\
\hline Other & $14(13.1 \%)$ & $9(15.5 \%)$ & $5(10.2 \%)$ & \\
\hline AIDS - N (\%) & $68(63.6 \%)$ & $38(65.5 \%)$ & $30(61.2 \%)$ & 0.554 \\
\hline ART use - N (\%) & $84(78.5 \%)$ & $45(77.6 \%)$ & $39(79.6 \%)$ & 0.956 \\
\hline Plasma HIV VL undetectable - N (\%) & $53(49.5 \%)$ & $29(50.0 \%)$ & $24(50.0 \%)$ & 0.838 \\
\hline CSF HIV VL undetectable - N (\%) & $79(73.8 \%)$ & $44(75.9 \%)$ & $36(73.5 \%)$ & 0.910 \\
\hline Current CD4+ count (<200 cells/mL) - N (\%) & $22(20.8 \%)$ & $9(15.5 \%)$ & $13(26.5 \%)$ & 0.160 \\
\hline Current CD4+ count - median (IQR) & 405 (216 to 582$)$ & 435 (260 to 589$)$ & $360(175$ to 531$)$ & 0.247 \\
\hline Albumin $(<5 \mathrm{~g} / \mathrm{dL})$ & $72(67.9 \%)$ & $37(64.9 \%)$ & $35(71.4 \%)$ & 0.474 \\
\hline Alcohol dependence - N (\%) & $25(23.2 \%)$ & $12(20.7 \%)$ & $13(26.5 \%)$ & 0.514 \\
\hline $\mathrm{HGB}($ mean $\pm \mathrm{SD})$ & $14.1 \pm 1.5$ & $14.1 \pm 1.6$ & $14.1 \pm 1.4$ & 0.882 \\
\hline AST - median (IQR) & 30 (23 to 37$)$ & 31 (24 to 39$)$ & 30 (22 to 36$)$ & 0.673 \\
\hline ALT - median (IQR) & 33 (22 to 43 ) & 36 (23 to 43 ) & 30 (22 to 40$)$ & 0.298 \\
\hline Body mass index (BMI) & & & & 0.290 \\
\hline $\mathrm{BMI} \leq 25$ & $45(42.1 \%)$ & $24(41.4 \%)$ & $21(42.9 \%)$ & \\
\hline $25<\mathrm{BMI}<30$ & 45 (42.1\%) & $22(37.9 \%)$ & $23(46.9 \%)$ & \\
\hline $\mathrm{BMI} \geq 30$ & $17(15.8 \%)$ & $12(20.7 \%)$ & $5(10.2 \%)$ & \\
\hline
\end{tabular}


Table 2 IGFs and related protein levels in the plasma and CSF

\begin{tabular}{lllllll}
\hline Factors & Plasma & & CSF & \multicolumn{2}{c}{ Ratio (CSF:plasma) } \\
\cline { 2 - 3 } & Median (IQR) $(\mathbf{n g} / \mathbf{m l})$ & References & & Median (IQR) (ng/ml) & References & \\
\hline IGF1 & $195.3(165.0$ to 224.8$)$ & {$[57,60-63]$} & & $1.11(0.92$ to 1.48$)$ & {$[61,64,65]$} & $1: 134$ \\
IGF2 & $693.9(587.2$ to 817.0$)$ & {$[60,62,64,66]$} & & $40.26(34.6$ to 45.4$)$ & {$[64,67]$} & $1: 17$ \\
IGFBP1 & $3.95(2.53$ to 7.01$)$ & {$[62,63,68]$} & & $0.48(0.35$ to 0.77$)$ & {$[68]$} & $1: 7$ \\
IGFBP2 & $33.97(14.44$ to 51.76$)$ & {$[60,62]$} & & $77.03(59.3$ to 101.2$)$ & {$[64,67]$} & $1: 0.4$ \\
IGF2R & $99.73(52.3$ to 176.3$)$ & {$[47,48,69,70]$} & $6.65(3.79$ to 10.00$)$ & None & $1: 17$ \\
\hline
\end{tabular}

$\mathrm{IQR}$, interquartile range.

with non-impaired (1.11 vs. 1.13), this was far from significant $(P=0.821)$. Similarly, both the plasma IGF1 (186.0 vs. 200.1 $P=0.127)$ and IGF2 (686.1 vs. $723.3, P=0.520)$ were reduced in the subgroup with NP impairment but without significance (see the 'Discussion' section).

\section{Analyses of plasma proteins}

\section{Multivariate analyses of factors associated with plasma} IGFs and related proteins

In order to examine the relationship between plasma IGF protein expression and the demographic and clinical factors as well as inflammation, we initially performed (1) univariate analyses of factors associated with plasma IGFs and related proteins and (2) correlation analyses of IGF proteins and inflammatory mediators as described under the 'Methods' section. The results are presented in Additional file 1: Table S1A and S1B, respectively. We additionally performed multivariate analyses for each of the plasma IGF proteins to determine significant associations. The results are shown in Tables 4, 5, 6, 7, and 8 . Table 4 shows multivariate analysis for plasma IGF1. Men had higher plasma IGF1 compared to women ( $\beta$ coefficient $=31.81, P=0.039)$. Older age $(\beta$ coefficient $=-1.31$, $P=0.033)$, AIDS $(\beta$ coefficient $=-18.91, P=0.081$ ) and higher AST ( $\beta$ coefficient $=-0.36, P=0.026$ ) were associated with lower plasma IGF1. NC impairment was not associated with plasma IGF1. Table 5 shows multivariate analysis for plasma IGF2. Lower IP-10 ( $\beta$ coefficient $=-125.0, P=0.017)$ and alcohol dependence ( $\beta$ coefficient $=71.8, P=0.023)$ were associated with higher plasma IGF2. NC impairment was not associated with plasma IGF2. Table 6 shows multivariate analysis for plasma IGFBP1. Higher IL-17 was associated with higher plasma IGFBP1 $(\beta$ coefficient $=0.28$, $P=0.009)$. Plasma IGFBP1 was lower in subjects with 25 $<$ BMI $<30$ ( $\beta$ coefficient $=-0.46, P=0.001)$ or subjects with $\mathrm{BMI} \geq 30$ ( $\beta$ coefficient $=-0.94, P<0.001)$ compared to subjects with $\mathrm{BMI} \leq 25$. Table 7 shows non-parametric multivariate analysis of plasma IGFBP2. Plasma IGFBP2 was higher in whites compared to blacks or other race $(P=0.027)$. Higher IL-6 was associated with higher plasma IGFBP2 $(P=0.021)$. NC impairment was not associated with plasma IGFBP2. Multivariate linear regression analysis of factors associated with plasma IGF2R is shown in Table 8. Men had lower plasma IGF2R compared to women $(\beta$ coefficient $=-0.48, P=0.042$ ). Detectable plasma VL $(\beta$ coefficient $=0.37, \quad P=0.021)$ and lower CD4 count $(\beta$ coefficient $=-0.04, P=0.021)$ were associated

Table 3 Comparison of IGFs and related proteins in plasma and CSF in subjects with or without neurocognitive impairment

\begin{tabular}{|c|c|c|c|c|c|}
\hline & Factors & $\begin{array}{l}\text { All subjects } \\
(n=107)\end{array}$ & $\begin{array}{l}\text { NC impaired } \\
(n=58)\end{array}$ & $\begin{array}{l}\text { NC unimpaired } \\
(n=49)\end{array}$ & $P$ value \\
\hline \multirow[t]{6}{*}{ Plasma } & IGF1 (mean \pm SD, ng/ml) & $192.5 \pm 55.3$ & $186.0 \pm 63.28$ & $200.1 \pm 43.7$ & 0.127 \\
\hline & IGF2 (mean $\pm \mathrm{SD}, \mathrm{ng} / \mathrm{ml})$ & $703.3 \pm 165.2$ & $686.1 \pm 170.5$ & $723.3 \pm 158.3$ & 0.520 \\
\hline & $\log$ IGFBP1 (mean \pm SD, ng/ml) ${ }^{\mathrm{a}}$ & $1.43 \pm 0.74$ & $1.45 \pm 0.85$ & $1.40 \pm 0.59$ & 0.797 \\
\hline & IGFBP2 - median (IQR) & 33.97 & 38.59 & 26.00 & 0.346 \\
\hline & & (14.44 to 51.76$)$ & (16.13 to 47.72$)$ & (6.54 to 54.39$)$ & \\
\hline & $\log$ IGF2R $(\text { mean } \pm S D, n g / m l)^{a}$ & $4.51 \pm 0.88$ & $4.47 \pm 0.97$ & $4.56 \pm 0.77$ & 0.716 \\
\hline \multirow[t]{5}{*}{ CSF } & IGF1 - median (IQR) & 1.11 (0.92 to 1.48$)$ & 1.11 (0.88 to 1.48$)$ & $1.13(0.92$ to 1.51$)$ & 0.821 \\
\hline & $\log$ IGF2 (mean \pm SD, ng/ml) ${ }^{\mathrm{a}}$ & $3.70 \pm 0.17$ & $3.72 \pm 0.17$ & $3.68 \pm 0.17$ & 0.345 \\
\hline & IGFBP1 - median (IQR) & 0.48 (0.35 to 0.77$)$ & 0.50 (0.37 to 0.75$)$ & 0.47 (0.33 to 1.59$)$ & 0.880 \\
\hline & $\log$ IGFBP2 (mean \pm SD, ng/ml) ${ }^{\mathrm{a}}$ & $4.35 \pm 0.37$ & $4.35 \pm 0.32$ & $4.36 \pm 0.41$ & 0.986 \\
\hline & $\mathrm{IGF} 2 \mathrm{R}^{0.5}(\text { mean } \pm \mathrm{SD}, \mathrm{ng} / \mathrm{ml})^{\mathrm{b}}$ & $2.56 \pm 0.84$ & $2.51 \pm 0.87$ & $2.62 \pm 0.80$ & 0.498 \\
\hline
\end{tabular}

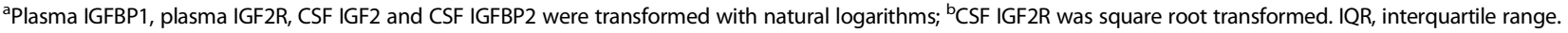


Table 4 Multivariate linear regression analysis of factors associated with plasma IGF1

\begin{tabular}{lll}
\hline Plasma characteristics & $\boldsymbol{\beta}$ coefficient (S.E.) & $\boldsymbol{P}$ value \\
\hline Neurocognitive impairment & $-8.48(10.45)$ & 0.418 \\
Gender, male & $31.81(15.2)$ & 0.039 \\
Age & $-1.31(0.61)$ & 0.033 \\
AIDS & $-18.91(10.74)$ & 0.081 \\
AST & $-0.36(0.16)$ & 0.026 \\
\hline
\end{tabular}

$\beta$ coefficients less than zero indicate an inverse association between the characteristic and plasma IGF1.

with higher plasma IGF2R. Higher IL-10 ( $\beta$ coefficient $=$ $0.18, P=0.061$ ) was associated with higher plasma IGF2R, but this result is borderline significance. NC impairment ( $\beta$ coefficient $=-0.03, P=0.859)$ was not associated with plasma IGF2R.

\section{Analyses of CSF proteins \\ Multivariate analyses of factors associated with CSF IGFs and related proteins}

Univariate analyses of factors associated with CSF IGFs and related proteins, as well as correlation analyses of CSF IGFs, related proteins and inflammatory mediators are presented in Additional file 1: Table S2A and S2B, respectively. Multivariate analyses of CSF IGF proteins are shows in Table 9. Table 9 shows multivariate analysis for CSF IGF1. Whites had higher CSF IGF1 compared to blacks or other race $(P=0.002)$. No association between CSF IGF1 and NC impairment was found. Table 10 shows multivariate analysis for CSF IGF2. Higher IP-10 ( $\beta$ coefficient $=0.11, P<0.001)$ and ART use $(\beta$ coefficient $=0.14, P<0.001$ ) were associated with higher CSF IGF2. Blacks $(\beta$ coefficient $=-0.12, P<0.001)$ or other race $(\beta$ coefficient $=-0.13, P=0.004)$ were associated with lower CSF IGF2. Alcohol dependence was also associated with lower CSF IGF2 ( $\beta$ coefficient $=-0.07, P=$ 0.029). There was no association between CSF IGF2 and NC impairment. Table 11 shows non-parametric analysis of covariance of factors associated with CSF IGFBP1. CSF IGFBP1 was higher in subjects with AIDS $(P=0.016)$ and alcohol dependence $(P=0.037)$. Higher CSF TNF $\alpha$ was associated with higher CSF IGFBP1 $(P<0.001)$. Higher BMI was associated with lower CSF IGFBP1 $(P<0.001)$. No association was found with NC impairment. Table 12

Table 5 Multivariate linear regression analysis of factors associated with plasma IGF2

\begin{tabular}{lll}
\hline Plasma characteristics & $\boldsymbol{\beta}$ coefficient (S.E.) & $\boldsymbol{P}$ value \\
\hline Neurocognitive impairment & $-21.9(31.0)$ & 0.482 \\
IP-10, per $\log _{10}$ & $-125.0(51.5)$ & 0.017 \\
Alcohol dependence & $71.8(31.3)$ & 0.023
\end{tabular}

$\beta$ coefficients less than zero indicate an inverse association between the characteristic and plasma IGF2.
Table 6 Multivariate linear regression analysis of factors associated with plasma IGFBP1

\begin{tabular}{lll}
\hline Plasma characteristics & $\boldsymbol{\beta}$ coefficient (S.E.) & $\boldsymbol{P}$ value \\
\hline Neurocognitive impairment & $0.14(0.13)$ & 0.261 \\
IL-17, per $\log _{10}$ & $0.28(0.11)$ & 0.009 \\
$25<\mathrm{BMI}<30$ (reference: $\mathrm{BMI} \leq 25)$ & $-0.46(0.14)$ & 0.001 \\
$\mathrm{BMI} \geq 30$ (reference: $\mathrm{BMI} \leq 25)$ & $-0.94(0.18)$ & $<0.001$ \\
\hline
\end{tabular}

$\beta$ coefficients less than zero indicate an inverse association between the characteristic and plasma IGFBP1.

shows multivariate analysis for CSF IGFBP2. Higher CSF TNF $\alpha$ was associated with higher CSF IGFBP2 ( $\beta$ coefficient $=0.14, P<0.001)$. No association was found with other factors. Table 13 shows multivariate analysis for CSF soluble IGF2R. Older age was associated with higher CSF IGF2R ( $\beta$ coefficient $=0.03, P=0.002$ ). Alcohol dependence was associated with lower CSF IGF2R ( $\beta$ coefficient $=-0.35, P=0.049)$. Blacks had lower CSF IGF2R compared to whites ( $\beta$ coefficient $=-0.31, P=0.068$ ) while other race had higher CSF IGF2R compared to white ( $\beta$ coefficient $=0.49, P=0.035$ ). There was no significant association between CSF IGF2R and NC impairment.

\section{Multivariate analyses of IGFs stratified by ART regimen}

We analyzed whether IGF protein levels differ based on the ART regimen. Of the 86 subjects with ART, 36 received non-nucleotide reverse transcriptase inhibitors (NNRTI)-based regimen and 40 received protease inhibitors (PI)-based regimen, and 8 received combined regimen. Univariate analyses of IGFs stratified by ART regimen are presented in Additional file 1: Table S3, and multivariate analyses are shown in Table 14. The results show that mean plasma IGF1 levels were lower in subjects on NNRTI-based regimen compared to those on PI-based regimen $(174.1 \pm 59.8$ vs. $202.8 \pm 47.3)$, and this difference was highly significant on multivariate analysis $(P=0.008)$. Other plasma IGF proteins did not differ significantly in the two subgroups. There were no

Table 7 Non-parametric analysis of covariance of factors associated with plasma IGFBP2

\begin{tabular}{llll}
\hline Plasma characteristics & & Median (IQR) & $\boldsymbol{P}$ value \\
\hline Neurocognitive impairment & & & 0.624 \\
& Yes & $38.59(16.53$ to 47.72) & \\
& No & $26.0(6.54$ to 54.39) &
\end{tabular}

Race

$$
\begin{array}{ll}
\text { Black } & 24.57 \text { (3.90 to } 45.44) \\
\text { Other } & 15.08(6.54 \text { to } 44.26) \\
\text { White } & 40.84 \text { (22.09 to } 54.39)
\end{array}
$$$$
\text { IL-6 } 0.209^{\mathrm{a}} \quad 0.021
$$

${ }^{\mathrm{a} S p e a r m a n}$ correlation coefficient between IL-6 and plasma IGFBP2. IQR, interquartile range. 
Table 8 Multivariate linear regression analysis of factors associated with plasma IGF2R

\begin{tabular}{lll}
\hline Plasma characteristics & $\boldsymbol{\beta}$ coefficient (S.E.) & $\boldsymbol{P}$ value \\
\hline Neurocognitive impairment & $-0.03(0.16)$ & 0.859 \\
Gender, male & $-0.48(0.23)$ & 0.042 \\
Current CD4+ count, per 50 copies & $-0.04(0.02)$ & 0.021 \\
Detectable HIV VL & $0.37(0.16)$ & 0.021 \\
IL-10, per 10 units & $0.18(0.10)$ & 0.061 \\
\hline
\end{tabular}

$\beta$ coefficients less than zero indicate an inverse association between the characteristic and plasma IGF2R.

significant differences in CSF IGF proteins between subjects on NNRTI-based regimen and those on PI-based regimen.

\section{Discussion}

Our analyses of IGF proteins included association with demographic and clinical parameters which confirmed many of the previously known associations, such as with age, gender, race, BMI, and liver function. As these factors have rarely been examined in the CSF, our study also provides useful information in comparison to their plasma levels. For example, while plasma IGF1 levels decreased with aging (as reported [26]), CSF IGF2R (as well as IGF1 and IGF2 levels) tended to increase with aging. Black race was associated with lower plasma levels of IGF family proteins (as reported [50,51]), and their levels (IGF1, IGF2, and IGF2R) measured in the CSF were also lower in Blacks. Lower IGFBP1 levels in both plasma and CSF were strongly $(P<0.001)$ associated with high BMI [52]. Alternations of many CSF IGF family proteins were also associated with alcohol dependence. While we cannot explain exact mechanisms

Table 9 Non-parametric analysis of covariance of factors associated with CSF IGF1

\begin{tabular}{lll}
\hline CSF characteristics & Median (IQR) & $\boldsymbol{P}$ value \\
\hline $\begin{array}{l}\text { Neurocognitive impairment } \\
\text { Yes }\end{array}$ & $1.11(0.88$ to 1.48$)$ & 0.557 \\
No & $1.18(0.92$ to 1.48$)$ & \\
Race & & \\
Black & $0.92(0.73$ to 1.29$)$ & 0.002 \\
Other & $1.09(0.95$ to 1.48$)$ & \\
White & $1.22(0.99$ to 1.71$)$ & \\
Alcohol dependence & & \\
No & $1.07(0.88$ to 1.48$)$ & 0.042 \\
Yes & $1.29(1.03$ to 1.82$)$ & \\
Age & $0.16^{\mathrm{a}}$ & 0.075 \\
\hline
\end{tabular}

${ }^{\mathrm{a} S p e a r m a n}$ correlation coefficient between age and CSF IGF1. IQR, interquartile range.
Table 10 Multivariate linear regression analysis of factors associated with CSF IGF2

\begin{tabular}{lll}
\hline CSF characteristics & $\boldsymbol{\beta}$ coefficient (S.E.) & $\boldsymbol{P}$ value \\
\hline Neurocognitive impairment & $0.02(0.03)$ & 0.429 \\
Black race (reference $=$ White) & $-0.12(0.03)$ & $<0.001$ \\
Other race (reference $=$ White) & $-0.13(0.04)$ & 0.004 \\
ART use & $0.14(0.04)$ & $<0.001$ \\
IP-10, per $\log _{10}$ & $0.11(0.02)$ & $<0.001$ \\
Alcohol dependence & $-0.07(0.03)$ & 0.029
\end{tabular}

$\beta$ coefficients less than zero indicate an inverse association between the characteristic and CSF IGF2.

for these associations, our data suggest that IGF proteins play dynamic and complex roles under physiologic and pathologic conditions and form the basis for future studies.

There are well-known associations between certain IGF family proteins, suggesting that their productions are coordinately regulated. Our study confirms some of these associations and provides additional information on their relationships (see the 'Results' section including Additional file 1). For example, in plasma, IGF1 and IGF2 were closely correlated and IGFBP1 and IGFBP2 were closely correlated (Additional file 1: Table S1B).

Table 11 Non-parametric analysis of covariance of factors associated with CSF IGFBP1

\begin{tabular}{|c|c|c|c|}
\hline CSF characteristics & & Median (IQR) & $P$ value \\
\hline \multirow[t]{3}{*}{ Neurocognitive impairment } & & & 0.613 \\
\hline & Yes & 0.49 (0.37 to 0.75$)$ & \\
\hline & No & 0.47 (0.33 to 1.62 ) & \\
\hline \multirow[t]{3}{*}{ AIDS } & & & 0.016 \\
\hline & Yes & 0.49 (0.36 to 1.17$)$ & \\
\hline & No & 0.44 (0.34 to 0.65$)$ & \\
\hline \multirow[t]{4}{*}{ Body mass index (BMI) } & & & $<0.001$ \\
\hline & $\mathrm{BMI} \leq 25$ & 0.60 (0.46 to 1.53$)$ & \\
\hline & $25<\mathrm{BMl}<30$ & 0.41 (0.33 to 0.66 ) & \\
\hline & $\mathrm{BMI} \geq 30$ & 0.37 (0.23 to 0.40$)$ & \\
\hline \multirow[t]{3}{*}{ Alcohol dependence } & & & 0.037 \\
\hline & Yes & 0.64 (0.40 to 1.62 ) & \\
\hline & No & 0.43 (0.34 to 0.72 ) & \\
\hline \multirow[t]{3}{*}{ Albumin } & & & 0.061 \\
\hline & 3 or 4 & 0.48 (0.37 to 1.50$)$ & \\
\hline & 5 & 0.44 (0.30 to 0.62 ) & \\
\hline TNF-a & & $0.394^{\mathrm{a}}$ & $<0.001$ \\
\hline Current CD4 Count & & $-0.044^{b}$ & 0.067 \\
\hline
\end{tabular}

${ }^{\mathrm{a}}$ Spearman correlation coefficient between TNF- $a$ and CSF IGFBP1; ${ }^{\mathrm{b}}$ Spearman correlation coefficient between current CD4 count and CSF IGFBP1. IQR, interquartile range. 
Table 12 Multivariate linear regression analysis of factors associated with CSF IGFBP2

\begin{tabular}{lll}
\hline CSF characteristics & $\boldsymbol{\beta}$ coefficient (S.E.) & $\boldsymbol{P}$ value \\
\hline Neurocognitive impairment & $0.01(0.07)$ & 0.861 \\
TNF-a, per $\log _{10}$ & $0.14(0.03)$ & $<0.001$ \\
\hline
\end{tabular}

$\beta$ coefficients less than zero indicate an inverse association between the characteristic and CSF IGFBP2.

Inflammatory mediators showed positive correlations with IGFBP1/IGFBP2 and negative correlations with IGF1/IGF2, indicating that inflammation suppresses IGF1/IGF2 production (Additional file 1: Table S1B). The inflammatory mediators that showed correlations included IL-6, which is an established biomarker for systemic inflammation in HIV + individuals [53], as well as the newly defined proinflammatory cytokine IL-17. These findings together suggest that inflammation is a highly significant underlying mechanism that regulates plasma IGF protein levels. IGF2R, which has not been examined in the context of HIV until now, showed a correlation with IGFBP1 and IGFBP2, as well as all of the inflammatory mediators examined (IL-17, IFN $\gamma$, IL-10, TNF- $\alpha$, IL-6, and MCP-1) except IP-10 on univariate analyses (Additional file 1: Table S1B). These results suggest that plasma IGF2R is induced by inflammatory mediators and is a potential biomarker for systemic inflammation in HIV+ individuals.

In our study, we also find that ART use was associated with alternations of plasma and CSF IGF protein levels. Specifically, higher plasma IGF2, CSF IGF2, and CSF IGF2R levels were associated with ART use on univariate analysis (Additional file 1: Table S1A and Table 4), possibly reflecting virologic and immunologic improvements associated with ART. Another important change in the IGF axis relates to the types of ART. For example, in our cohort, lower IGF1 levels were strongly associated with non-nucleotide reverse transcriptase inhibitors (NNRTI)-based regimen compared to protease inhibitors (PI)-based regimen $(P=0.008)$. This is consistent with the notion that efavirenz-induced vitamin $\mathrm{D}$ deficiency caused circulating IGF-1 deficiency in our cohort, as (1) efavirenz has been reported to induce vitamin D

Table 13 Multivariate linear regression analysis of factors associated with CSF IGF2R

\begin{tabular}{lll}
\hline CSF characteristics & $\boldsymbol{\beta}$ coefficient (S.E.) & $\boldsymbol{P}$ value \\
\hline Neurocognitive impairment & $-0.24(0.15)$ & 0.121 \\
Age, per year & $0.03(0.01)$ & 0.002 \\
Black race (reference $=$ White) & $-0.31(0.17)$ & 0.068 \\
Other race (reference $=$ White) & $0.49(0.23)$ & 0.035 \\
Alcohol dependence & $-0.35(0.18)$ & 0.049
\end{tabular}

$\beta$ coefficients less than zero indicate an inverse association between the characteristic and CSF IGF2R.
Table 14 Multivariate linear regression analysis of factors associated with plasma IGF1 in 76 subjects on ART

\begin{tabular}{lll}
\hline Plasma characteristics & $\boldsymbol{\beta}$ coefficient (S.E.) & $\boldsymbol{P}$ value \\
\hline Neurocognitive impairment & $-6.25(12.37)$ & 0.615 \\
AIDS & $-29.01(15.89)$ & 0.072 \\
$\mathrm{PI}^{\mathrm{a}}$ & $34.33(12.61)$ & 0.008 \\
AST & $-0.97(0.46)$ & 0.036 \\
\hline
\end{tabular}

$\beta$ coefficients less than zero indicate an inverse association between the characteristic and plasma IGF1. ${ }^{\mathrm{a}} 37$ on NNTRI-based and 40 on PI-based regimen (see text).

deficiency [39], (2) vitamin D is a known modulator of circulating IGF1 [38], and (3) efavirenz is the main NNRTI used by CHARTER subjects. These results add significantly to the notion that toxicity related to ART can contribute to neurocognitive impairment, in part, through growth factor depletion.

Analyses of CSF revealed that IGF2R levels correlated with IGF2 but not with other proteins or with inflammatory mediators (Additional file 1: Table S2B). These results may reflect that the source of CSF IGF2R in this cohort is mostly neuronal with little or no contributions from microglia or macrophages. This is consistent with our previous study which showed that de novo IGF2R induction in microglia is found in HIV encephalitis but not in most $\mathrm{HIV}+$ (but HIVE-) brains [46]. In the CSF, IGF2 appears to play a more significant role than IGF1. First, the IGF2: IGF1 ratios were considerably higher in the CSF (approximately 40:1) than plasma (approximately 3:1), indicating intrathecal production. Second, CSF IGF2 showed correlations with most other CSF factors including IGF2R, IGF1, IGFBP1, IGFBP2, IL-10, IP-10, and TNF $\alpha$ (Additional file 1: Table S2B). Furthermore, CSF IGFBP1 correlated with CSF IGFBP2, and both IGFBPs correlated with inflammatory mediators. The correlations were most significant with IGFBP2, whose CSF levels were higher than those in plasma, again indicating intrathecal production. The emerging picture is then IGF2 and IGFBP2 are the major IGF family proteins in the CSF/CNS. The source of IGF2 in the CSF compartment includes the choroid plexus and the meninges [14]. We found in vitro that while both IGFs were equally neuroprotective, IGF2 was upregulated and IGF1 was downregulated by proinflammatory mediators in cultured microglia [13], suggesting that the two IGFs may not (necessarily) be co-regulated in the CNS. The potential source of IGF1 in the brain and CSF compartment is also multiple including monocyte-lineage cells and other mesenchymal cells [13]. However, because intrathecal IGF1 production is minimal compared to systemic circulation, the most important source of CSF IGF1 might be circulating IGF1 [18]. Furthermore, as IGF2R is a scavenging receptor for both IGFs, upregulated IGF2R expression in CSF/CNS (in HIV encephalitis, for instance 
[46]) could function as a significant modulator of IGF protein expression. For instance, soluble IGF2R shed from cells (such as activated microglia and macrophages) can capture IGF2 and IGF1, effectively blocking their binding to cognate signaling receptor IGF1R. In this regard, the soluble IGF2R we detect in plasma/CSF should be considered a kind of IGF1R antagonist.

Our study confirms some of the reported IGF axis alterations associated with HIV infection and also adds new data. The association of low plasma IGF1 (or IGF2) and high IGFBPs with HIV progression (AIDS, low CD4 T cell counts) have been well established [28,31-33,54-56]. We also show for the first time that increased plasma IGF2R is associated with detectable plasma VL and low CD4+ T cell counts. As de novo IGF2R expression occurs in human microglia in HIV encephalitis (a model of tissue macrophages HIV infection) and IGF2R is a cellular cofactor for HIV replication [46], our biomarker data supports that IGF2R (likely induced by inflammatory mediators) boosts HIV replication (hence detectable VL) and induces $\mathrm{CD} 4+\mathrm{T}$ cell depletion. Together, these results show a novel finding that IGF2R is an important new player in the IGF axis that connects inflammation, HIV replication, and growth factor depletion.

We initially hypothesized that lower CSF IGF1 might be associated with NC impairment in HIV+ individuals but our hypothesis has not been borne out by our analyses. There are several possible reasons for this. First, the CSF IGF1 levels are very low (approximately 1/100 to $1 / 200$ of plasma levels) and therefore proving our hypothesis may require a much larger cohort. Second, the IGF axis has been shown to exhibit great inter-individual heterogeneity. For example, longitudinal analysis of 1,422 HIV+ women showed only a trend for association between low IGF1 levels and HIV disease progression [57]. In our analysis of 107 HIV+ subjects, plasma IGF1 and IGF2 levels as well as CSF IGF1 levels were lower in NC impaired $(n=58)$ compared to those in NC unimpaired $(n=49)$ subjects, though they were not statistically significant. Of the three, plasma IGF1 showed the largest difference between the two groups (186.5 $\pm 63.28 v s .200 .1 \pm 43.7, P=0.127)$, possibly suggesting that a much larger cohort may have shown a significant association between low plasma IGF1 and NC impairment. Furthermore, a combined growth factor deficiency (rather than a single deficiency) may contribute to significant functional outcome. In this regard, positive correlation between CSF IGF1 and CSF progranulin in our cohort $(r=0.26$, $P=0.008$ ) (Additional file 1: Table S2B) suggests a common mechanism of growth factor regulation in HIV+ individuals and lend further support to this hypothesis. Given the number of studies hinting at the role of CNS growth factor deficiencies in HAND [43,58,59], further studies are warranted to examine their potential roles in the pathogenesis and this complex CNS disorder.

\section{Additional file}

Additional file 1: Univariate analyses of factors associated with plasma and CSF insulin-like growth factors and related proteins.

\section{Competing interests}

The authors declare that they have no competing interests.

\section{Authors' contributions}

$H S, Y L$, and SCL designed the study and interpreted data. HS and NC performed ELISA. YL and HS performed statistical analyses. HS, YL, SL, and $\mathrm{SCL}$ wrote the paper. All authors read and approved the final manuscript.

\section{Acknowledgements}

This study was supported by the NIH grants K01MH084705, R01MH55477, Einstein CFAR (P30Al051519), and the CNS HIV Antiretroviral Therapy Effects Research (CHARTER). We are grateful to Robin Squeglia at the Einstein Biomarker Analytic Research Core (BARC) Laboratory for assisting with the IGF assays and Dr. Susan Morgello for her support throughout the study. CHARTER was supported by the $\mathrm{NIH}$ grants N01 MH22005, HHSN271201000036C, and HHSN271201000030C. The views expressed in this article are those of the authors and do not reflect the official policy or position of the United States Government.

The CNS HIV Antiretroviral Therapy Effects Research (CHARTER) group is affiliated with Johns Hopkins University; the Icahn School of Medicine at Mount Sinai; University of California, San Diego; University of Texas, Galveston; University of Washington, Seattle; Washington University, St. Louis; and is headquartered at the University of California, San Diego and includes: Director: Igor Grant, M.D.; Co-Directors: Scott L. Letendre, M.D., Ronald J. Ellis, M.D., Ph.D., Thomas D. Marcotte, Ph.D.; Center Manager: Donald Franklin, Jr.; Neuromedical Component: Ronald J. Ellis, M.D., Ph.D. (P.I.), J. Allen

McCutchan, M.D.; Laboratory and Virology Component: Scott Letendre, M.D. (Co-P.I.), Davey M. Smith, M.D. (Co-P.I.).; Neurobehavioral Component: Robert K. Heaton, Ph.D. (P.I.), J. Hampton Atkinson, M.D., Matthew Dawson; Imaging Component: Christine Fennema-Notestine, Ph.D. (P.I.), Michael J Taylor, Ph.D., Rebecca Theilmann, Ph.D.; Data Management Component: Anthony C. Gamst, Ph.D. (P.I.), Clint Cushman; Statistics Component: Ian Abramson, Ph.D. (P.I.), Florin Vaida, Ph.D., Reena Deutsch, Ph.D.; Johns Hopkins University Site: Justin McArthur (P.I.), Vincent Rogalski; Icahn School of Medicine at Mount Sinai Site: Susan Morgello, M.D. (Co-P.I.) and David Simpson, M.D. (Co-P.I.), Letty Mintz, N.P.; University of California, San Diego Site: J. Allen McCutchan, M.D. (P.I.), Kaori Phillips, B.S.N.; University of Washington, Seattle Site: Ann Collier, M.D. (Co-P.I.) and Christina Marra, M.D. (Co-P.I.), Trudy Jones, M.N., A.R.N.P.; University of Texas, Galveston Site: Benjamin Gelman, M.D., Ph. D. (P.I.), Eleanor Head, R.N., B.S.N.; and Washington University, St. Louis Site: David Clifford, M.D. (P.I.), Muhammad Al-Lozi, M.D., Mengesha Teshome, M.D.

\section{Author details}

${ }^{1}$ Department of Pathology, Albert Einstein College of Medicine, Bronx, NY 10461, USA. ${ }^{2}$ Department of Epidemiology and Population Health, Albert Einstein College of Medicine, Bronx, NY 10461, USA. ${ }^{3}$ Department of Neurology, University of California San Diego, 9500 Gilman Dr, La Jolla, CA 92093, USA.

Received: 9 January 2015 Accepted: 24 March 2015

Published online: 15 April 2015

\section{References}

1. Bondy CA, Cheng CM. Signaling by insulin-like growth factor 1 in brain. Eur J Pharmacol. 2004;490:25-31.

2. Baxter RC. Insulin-like growth factor (IGF)-binding proteins: interactions with IGFs and intrinsic bioactivities. Am J Physiol Endocrinol Metab. 2000;278:E967-76.

3. Russo VC, Gluckman PD, Feldman EL, Werther GA. The insulin-like growth factor system and its pleiotropic functions in brain. Endocr Rev. 2005;26:916-43.

4. Platz EA, Pollak MN, Rimm EB, Majeed N, Tao Y, Willett WC, et al. Racial variation in insulin-like growth factor-1 and binding protein-3 concentrations in middle-aged men. Cancer Epidemiol Biomarkers Prev. 1999;8:1107-10.

5. Pollak MN, Schernhammer ES, Hankinson SE. Insulin-like growth factors and neoplasia. Nat Rev Cancer. 2004;4:505-18.

6. O'Dell SD, Day IN. Insulin-like growth factor II (IGF-II). Int J Biochem Cell Biol. 1998;30:767-71. 
7. Congote LF. Monitoring insulin-like growth factors in HIV infection and AIDS. Clin Chim Acta. 2005;361:30-53.

8. Han VK, D'Ercole AJ, Lund PK. Cellular localization of somatomedin (insulin-like growth factor) messenger RNA in the human fetus. Science. 1987;236:193-7.

9. Kihira T, Suzuki A, Kubo T, Miwa H, Kondo T. Expression of insulin-like growth factor-II and leukemia inhibitory factor antibody immunostaining on the ionized calcium-binding adaptor molecule 1-positive microglias in the spinal cord of amyotrophic lateral sclerosis patients. Neuropathology. 2007;27:257-68.

10. Haselbacher GK, Schwab ME, Pasi A, Humbel RE. Insulin-like growth factor II (IGF II) in human brain: regional distribution of IGF II and of higher molecular mass forms. Proc Natl Acad Sci U S A. 1985;82:2153-7.

11. Chen DY, Stern SA, Garcia-Osta A, Saunier-Rebori B, Pollonini G, Bambah-Mukku $D$, et al. A critical role for IGF-II in memory consolidation and enhancement. Nature. 2011:469:491-7.

12. Carson MJ, Behringer RR, Brinster RL, McMorris FA. Insulin-like growth factor I increases brain growth and central nervous system myelination in transgenic mice. Neuron. 1993;10:729-40.

13. Suh HS, Zhao ML, Derico L, Choi N, Lee SC. Insulin-like growth factor 1 and 2 (IGF1, IGF2) expression in human microglia: differential regulation by inflammatory mediators. J Neuroinflammation. 2013;10:37.

14. Fernandez AM, Torres-Aleman I. The many faces of insulin-like peptide signalling in the brain. Nat Rev Neurosci. 2012;13:225-39.

15. Ghosh P, Dahms NM, Kornfeld S. Mannose 6-phosphate receptors: new twists in the tale. Nat Rev Mol Cell Biol. 2003;4:202-12.

16. Hawkes C, Kar S. The insulin-like growth factor--1//mannose-6-phosphate receptor: structure, distribution and function in the central nervous system. Brain Res Brain Res Rev. 2004;44:117-40.

17. Firth SM, Baxter RC. Cellular actions of the insulin-like growth factor binding proteins. Endocr Rev. 2002;23:824-54.

18. Benarroch EE. Insulin-like growth factors in the brain and their potential clinical implications. Neurology. 2012;79:2148-53.

19. Samstein B, Hoimes ML, Fan J, Frost RA, Gelato MC, Lang CH. IL-6 stimulation of insulin-like growth factor binding protein (IGFBP)-1 production. Biochem Biophys Res Commun. 1996;228:611-5.

20. Lang $\mathrm{CH}$, Nystrom GJ, Frost RA. Regulation of IGF binding protein-1 in hep G2 cells by cytokines and reactive oxygen species. Am J Physiol. 1999;276:G719-27.

21. Wheatcroft SB, Kearney MT. IGF-dependent and IGF-independent actions of IGF-binding protein-1 and -2: implications for metabolic homeostasis. Trends Endocrinol Metab. 2009:20:153-62.

22. Alvarez A, Cacabelos R, Sanpedro C, Garcia-Fantini M, Aleixandre M. Serum TNF-alpha levels are increased and correlate negatively with free IGF-I in Alzheimer disease. Neurobiol Aging. 2007;28:533-6.

23. Bilic E, Bilic E, Rudan I, Kusec V, Zurak N, Delimar D, et al. Comparison of the growth hormone, IGF-1 and insulin in cerebrospinal fluid and serum between patients with motor neuron disease and healthy controls. Eur J Neurol. 2006;13:1340-5.

24. Pulford BE, Ishii DN. Uptake of circulating insulin-like growth factors (IGFs) into cerebrospinal fluid appears to be independent of the IGF receptors as well as IGF-binding proteins. Endocrinology. 2001;142:213-20.

25. Carro E, Trejo JL, Busiguina S, Torres-Aleman I. Circulating insulin-like growth factor I mediates the protective effects of physical exercise against brain insults of different etiology and anatomy. J Neurosci. 2001;21:5678-84.

26. van Dam PS, Aleman A. Insulin-like growth factor-I, cognition and brain aging. Eur J Pharmacol. 2004;490:87-95.

27. Clark R. The somatogenic hormones and insulin-like growth factor-1: stimulators of lymphopoiesis and immune function. Endocr Rev. 1997:18:157-79.

28. Helle SI, Ueland T, Ekse D, Froland SS, Holly JM, Lonning PE, et al. The insulin-like growth factor system in human immunodeficiency virus infection: relations to immunological parameters, disease progression, and antiretroviral therapy. J Clin Endocrinol Metab. 2001;86:227-33.

29. Blackman MR. Manipulation of the growth hormone axis in patients with HIV infection. N Engl J Med. 2007;357:2397-9.

30. Falutz J, Allas S, Blot K, Potvin D, Kotler D, Somero M, et al. Metabolic effects of a growth hormone-releasing factor in patients with HIV. N Engl J Med. 2007:357:2359-70.

31. Mynarcik DC, Frost RA, Lang CH, DeCristofaro K, McNurlan MA, Garlick PJ, et al. Insulin-like growth factor system in patients with HIV infection: effect of exogenous growth hormone administration. J Acquir Immune Defic Syndr. 1999;22:49-55.

32. Frost RA, Fuhrer J, Steigbigel R, Mariuz P, Lang CH, Gelato MC. Wasting in the acquired immune deficiency syndrome is associated with multiple defects in the serum insulin-like growth factor system. Clin Endocrinol (Oxf). 1996:44:501-14

33. Haugaard SB, Andersen $O$, Hansen BR, Orskov H, Andersen UB, Madsbad S, et al. Insulin-like growth factors, insulin-like growth factor-binding proteins, insulin-like growth factor-binding protein-3 protease, and growth hormonebinding protein in lipodystrophic human immunodeficiency virus-infected patients. Metabolism. 2004;53:1565-73.

34. Parfieniuk-Kowerda A, Czaban SL, Grzeszczuk A, Jaroszewicz J, Flisiak R Assessment of serum IGF-1 and adipokines related to metabolic dysfunction in HIV-infected adults. Cytokine. 2013;64:97-102.

35. Brown TT, Glesby MJ. Management of the metabolic effects of HIV and HIV drugs. Nat Rev Endocrinol. 2012;8:11-21

36. Cassol E, Misra V, Morgello S, Gabuzda D. Applications and limitations of inflammatory biomarkers for studies on neurocognitive impairment in HIV infection. J Neuroimmune Pharmacol. 2013;8:1087-97.

37. Galescu O, Bhangoo A, Ten S. Insulin resistance, lipodystrophy and cardiometabolic syndrome in HIV/AIDS. Rev Endocr Metab Disord. 2013:14:133-40.

38. Ameri P, Giusti A, Boschetti M, Bovio M, Teti C, Leoncini $G$, et al. Vitamin D increases circulating IGF1 in adults: potential implication for the treatment of GH deficiency. Eur J Endocrinol. 2013;169:767-72.

39. Wohl DA, Orkin C, Doroana M, Pilotto JH, Sungkanuparph S, Yeni P, et al. Change in vitamin $D$ levels and risk of severe vitamin D deficiency over 48 weeks among HIV-1-infected, treatment-naive adults receiving rilpivirine or efavirenz in a phase III trial (ECHO). Antivir Ther. 2014;19:191-200.

40. Heaton RK, Clifford DB, Franklin Jr DR, Woods SP, Ake C, Vaida F, et al. HIV-associated neurocognitive disorders persist in the era of potent antiretroviral therapy: CHARTER Study. Neurology. 2010;75:2087-96.

41. McArthur JC, Steiner J, Sacktor N, Nath A. Human immunodeficiency virusassociated neurocognitive disorders: mind the gap. Ann Neurol. 2010;67:699-714.

42. Antinori A, Arendt G, Becker JT, Brew BJ, Byrd DA, Cherner M, et al. Updated research nosology for HIV-associated neurocognitive disorders. Neurology. 2007:69:1789-99.

43. Suh HS, Lo Y, Choi N, Letendre S, Lee SC. Evidence of the innate antiviral and neuroprotective properties of progranulin. PLoS One. 2014;9, e98184.

44. Suh HS, Gelman BB, Lee SC. Potential roles of microglial cell progranulin in HIV-associated CNS pathologies and neurocognitive impairment. J Neuroimmune Pharmacol. 2013;9:117-32.

45. Suh HS, Choi N, Tarassishin L, Lee SC. Regulation of progranulin expression in human microglia and proteolysis of progranulin by matrix metalloproteinase-12 (MMP-12). PLoS One. 2012;7, e35115.

46. Suh HS, Cosenza-Nashat M, Choi N, Zhao ML, Li JF, Pollard JW, et al. Insulin-like growth factor 2 receptor is an IFNgamma-inducible microglial protein that facilitates intracellular HIV replication: implications for HIV-induced neurocognitive disorders. Am J Pathol. 2010;177:2446-58.

47. Jeyaratnaganthan N, Hojlund K, Kroustrup JP, Larsen JF, Bjerre M, Levin K, et al. Circulating levels of insulin-like growth factor-II/mannose-6-phosphate receptor in obesity and type 2 diabetes. Growth Horm IGF Res. 2010;20:185-91.

48. El-Shewy HM, Luttrell LM. Insulin-like growth factor-2/mannose-6 phosphate receptors. Vitam Horm. 2009:80:667-97.

49. Woods SP, Rippeth JD, Frol AB, Levy JK, Ryan E, Soukup VM, et al. Interrater reliability of clinical ratings and neurocognitive diagnoses in HIV. J Clin Exp Neuropsychol. 2004;26:759-78.

50. Colangelo LA, Liu K, Gapstur SM. Insulin-like growth factor-1, insulin-like growth factor binding protein-3, and cardiovascular disease risk factors in young black men and white men: the CARDIA male hormone study. Am J Epidemiol. 2004;160:750-7.

51. Gapstur SM, Kopp P, Chiu BC, Gann PH, Colangelo LA, Liu K. Longitudinal associations of age, anthropometric and lifestyle factors with serum tota insulin-like growth factor-I and IGF binding protein-3 levels in Black and White men: the CARDIA male hormone study. Cancer Epidemiol Biomarkers Prev. 2004;13:2208-16.

52. Kajantie E, Fall CH, Seppala M, Koistinen R, Dunkel L, Yliharsila $H$, et al. Serum insulin-like growth factor (IGF)-I and IGF-binding protein-1 in elderly people: relationships with cardiovascular risk factors, body composition, size at birth, and childhood growth. J Clin Endocrinol Metab. 2003;88:1059-65.

53. Airoldi M, Bandera A, Trabattoni D, Tagliabue B, Arosio B, Soria A, et al. Neurocognitive impairment in HIV-infected naive patients with advanced disease: the role of virus and intrathecal immune activation. Clin Dev Immunol. 2012;2012:467154.

54. Andersen O, Hansen BR, Troensegaard W, Flyvbjerg A, Madsbad S, Orskov H, et al. Sustained low-dose growth hormone therapy optimizes bioactive 
insulin-like growth factor-l level and may enhance CD4 T-cell number in HIV infection. J Med Virol. 2010;82:197-205.

55. Erlandson KM, Allshouse AA, Jankowski CM, MaWhinney S, Kohrt WM, Campbell TB. Functional impairment is associated with low bone and muscle mass among persons aging with HIV infection. J Acquir Immune Defic Syndr. 2013;63:209-15.

56. Lo J, You SM, Canavan B, Liebau J, Beltrani G, Koutkia P, et al. Low-dose physiological growth hormone in patients with HIV and abdominal fat accumulation: a randomized controlled trial. JAMA. 2008;300:509-19.

57. Strickler HD, Fazzari M, Kovacs A, Isasi C, Napolitano LA, Minkoff $H$, et al. Associations of insulin-like growth factor (IGF)-I and IGF-binding protein-3 with HIV disease progression in women. J Infect Dis. 2008;197:319-27.

58. Meeker RB, Poulton W, Markovic-Plese S, Hall C, Robertson K. Protein changes in CSF of HIV-infected patients: evidence for loss of neuroprotection. J Neurovirol. 2011;17:258-73.

59. Fields J, Dumaop W, Langford TD, Rockenstein E, Masliah E. Role of neurotrophic factor alterations in the neurodegenerative process in HIV associated neurocognitive disorders. J Neuroimmune Pharmacol. 2014;9:102-16.

60. Yu H, Mistry J, Nicar MJ, Khosravi MJ, Diamandis A, van Doorn J, et al. Insulin-like growth factors (IGF-I, free IGF-I and IGF-II) and insulin-like growth factor binding proteins (IGFBP-2, IGFBP-3, IGFBP-6, and ALS) in blood circulation. J Clin Lab Anal. 1999;13:166-72.

61. Kessler M, Kaul A, Santos-Malave C, Borkowsky W, Kessler J, Shah B. Growth patterns in pubertal HIV-infected adolescents and their correlation with cytokines, IGF-1, IGFBP-1, and IGFBP-3. J Pediatr Endocrinol Metab. 2013;26:639-44.

62. Narayanan RP, Fu B, Heald AH, Siddals KW, Oliver RL, Hudson JE, et al. IGFBP2 is a biomarker for predicting longitudinal deterioration in renal function in type 2 diabetes. Endocr Connect. 2012;1:95-102.

63. Yeap BB, Chubb SA, McCaul KA, Ho KK, Hankey GJ, Norman PE, et al. Associations of IGF1 and IGFBPs 1 and 3 with all-cause and cardiovascular mortality in older men: the health in men study. Eur J Endocrinol. 2011;164:715-23.

64. Hertze J, Nagga K, Minthon L, Hansson O. Changes in cerebrospinal fluid and blood plasma levels of IGF-II and its binding proteins in Alzheimer's disease: an observational study. BMC Neurol. 2014;14:64.

65. Johansson P, Aberg D, Johansson JO, Mattsson N, Hansson O, Ahren B, et al. Serum but not cerebrospinal fluid levels of insulin-like growth factor-I (IGF-I) and IGF-binding protein-3 (IGFBP-3) are increased in Alzheimer's disease. Psychoneuroendocrinology. 2013;38:1729-37.

66. Zhao R, Berho M, Nogueras J, Sands D, Weiss E, Wexner S, et al. Positive correlation of insulin-like growth factor-ll with proliferating cell index in patients with colorectal neoplasia. Cancer Epidemiol Biomarkers Prev. 2005;14:1819-22.

67. de Bont JM, van Doorn J, Reddingius RE, Graat GH, Passier MM, den Boer ML, et al. Various components of the insulin-like growth factor system in tumor tissue, cerebrospinal fluid and peripheral blood of pediatric medulloblastoma and ependymoma patients. Int I Cancer. 2008;123:594-600

68. Khosravi MJ, Diamandi A, Mistry J. Immunoassay of insulin-like growth factor binding protein-1. Clin Chem. 1997;43:523-32.

69. Bobek G, Scott CD, Baxter RC. Radioimmunoassay of soluble insulin-like growth factor-II/mannose 6-phosphate receptor: developmental regulation of receptor release by rat tissues in culture. Endocrinology. 1992;130:3387-94.

70. Costello M, Baxter RC, Scott CD. Regulation of soluble insulin-like growth factor II/mannose 6-phosphate receptor in human serum: measurement by enzyme-linked immunosorbent assay. J Clin Endocrinol Metab. 1999;84:611-7.

\section{Submit your next manuscript to BioMed Central and take full advantage of:}

- Convenient online submission

- Thorough peer review

- No space constraints or color figure charges

- Immediate publication on acceptance

- Inclusion in PubMed, CAS, Scopus and Google Scholar

- Research which is freely available for redistribution 